\title{
Fluid therapy in uncontrolled hemorrhage - what experimental models have taught us
}

\author{
Robert Hahn
}

\section{Linköping University Post Print}

\section{Tweet}

N.B.: When citing this work, cite the original article.

This is the pre-reviewed version of the following article:

Robert Hahn , Fluid therapy in uncontrolled hemorrhage - what experimental models have taught us, 2013, Acta Anaesthesiologica Scandinavica, (57), 1, 16-28.

which has been published in final form at:

http://dx.doi.org/10.1111/j.1399-6576.2012.02763.x

Copyright: Wiley-Blackwell

http://eu.wiley.com/WileyCDA/Brand/id-35.html

Postprint available at: Linköping University Electronic Press

http://urn.kb.se/resolve?urn=urn:nbn:se:liu:diva-87245 
Review Article

\section{Fluid therapy in uncontrolled hemorrhage}

What experimental models have taught us

Robert G. Hahn

Robert G. Hahn, Professor of Anesthesiology \& Intensive Care,

Linköping University, Linköping, Sweden;

Director of Research, Södertälje Hospital, Södertälje, Sweden.

Corresponding author:

Robert Hahn, MD, PhD

Research Unit, House 18

Södertälje Hospital,

58185 Södertälje, Sweden

Phone: +46739660972

Fax: +46855024671

E-mail: r.hahn@telia.com 


\begin{abstract}
Intravenous fluid is life-saving in hypovolemic shock, but fluid sometimes aggravates the bleeding. During the past 25 years, animal models have helped our understanding of the mechanisms involved in this unexpected effect. A key issue is that vasoconstriction is insufficient to arrest the bleeding when damage is made to a major blood vessel. "Uncontrolled hemorrhage" is rather stopped by a blood clot formed at the outside surface of the vessel, and the immature clot is sensitive to mechanical and chemical interactions. The mortality increases if rebleeding occurs.

In the aortic tear model in swine, hemorrhage volume and the mortality increase from effective restoration of the arterial pressure. The mortality versus amount of fluid curve is U-shaped with higher mortality at either end. Without any fluid at all, irreversible shock causes death provided the hemorrhage is sufficiently large. Crystalloid fluid administered in a 3:1 proportion to the amount of lost blood initiates serious rebleeding. Hypertonic saline $7.5 \%$ in $6 \%$ dextran 70 (HSD) also provokes rebleeding resulting in higher mortality in the recommended dosage of $4 \mathrm{ml} / \mathrm{kg}$. Uncontrolled hemorrhage models in rats, except for the "cut tail" model, confirm the results from swine.

To avoid rebleeding, fluid programs should not aim to fully restore the arterial pressure, blood flow rates, or blood volume. For a hemorrhage of 1,000 ml, computer simulations show that deliberate hypovolemia $(-300 \mathrm{ml})$ would be achieved by infusing $600-750 \mathrm{ml}$ crystalloid fluid over 20-30 min or $100 \mathrm{ml}$ of HSD over 10-20 min in an adult male.
\end{abstract}

Key words: hemorrhage, intravenous fluid, trauma, animal model, resuscitation, hypertonic saline dextran, hemostasis, mortality 

Our body has a complex physiologic response to bleeding that initially involves vasoconstriction and a reduction in blood flow rates. Later, there is arterial hypotension, hypoperfusion, and acidosis. The infusion of fluids can reverse all these signs of a reduced circulating blood volume, a truly life-saving remedy. Fluid therapy is undoubtedly a most crucial component in the treatment of hemorrhagic shock.

However, in some instances, clinical experience holds that fluid therapy can make things worse. With the infusion of fluid, the hemorrhage accelerates and the patient is soon in a desperate situation where nothing helps. Clinical situations associated with such detrimental effects of plasma volume expansion include gastric bleeding and aortic rupture. Others might include traumatic pelvic fractures, gunshot wounds, and traffic accidents. Warnings about the hazards of ambitious fluid therapy in treating penetrating injuries were given as early as during World War I, but the pathophysiology of such untoward reactions to fluid therapy has still remained obscure.

Only the use of experimental animal models has been able to provide a better understanding of why infusion fluids sometimes have effects opposite to the intended ones. The present review summarizes how experimental studies have gradually increased our knowledge in this field. Together with fluid volume kinetic data derived from volunteers, they form a rational basis to current concepts of fluid therapy management in hypotensive patients suffering from hypovolemic shock where definite surgical treatment is not immediately available.

\section{STUDIES IN PIGS}

Most research models of hemorrhagic shock are based on a controlled biological system where a certain amount of blood is removed or exsanguination is performed down to a predetermined arterial pressure. Bickell, Bruttig, \& Wade in 1989 developed an alternative hemorrhage model in swine, in which the bleeding is not controlled. ${ }^{1}$ This model appeared to be more clinically relevant than the controlled models. The pig is widely used for studies of hemorrhagic hypotension and shock as the hemodynamic responses are very similar to man. Their blood hemoglobin is slightly lower (average 
$110 \mathrm{~g} / \mathrm{L})^{2}$ and the coagulation system more effective than in humans. ${ }^{3}$

Anesthetized animals were surgically prepared and a needle, bent in a semicircle, was inserted into the aortic wall just below the kidneys. By pulling a wire affixed to the needle, the investigators could study the physiological consequences of an uncontrolled hemorrhage from a hole in the aorta having a width of exactly $0.5 \mathrm{~mm}$.

When hemorrhage occurred in such a major central blood vessel, the animals responded in a way typical of later stages of hemorrhage, even before the amount of blood lost had reached appreciable amounts. There was no vasoconstriction and the systemic arterial pressure dropped within 10 seconds after the wire was pulled. ${ }^{1}$ Other hemodynamic effects included a sharp drop in cardiac output (to $1 / 3$ of baseline).

Riddez, Johnson, \& Hahn improved the aortic tear model in $1998 .^{2,4,5}$ By placing a flow probe above and below the site of the aortic tear, researchers could monitor the rate of the hemorrhage as the difference in flow between the two probes (Fig. 1). The experiments were further refined by providing immediate feedback to the investigators about the rate of the hemorrhage, allowing crystalloid fluid replacement that was more precise in terms of the amount of blood lost. These modifications addressed a drawback of previous work with volume-by-volume replacement when the investigators never knew exactly how much blood had been lost in an individual animal until autopsy had been performed.

The double flow probe method showed that the rate of the initial hemorrhage decreased in an exponential manner and stopped completely within 4 minutes (half-time 40 seconds) in a pig weighing $20 \mathrm{~kg}^{4}$ (Fig. 2). The total amount of blood lost during this early phase averaged $35 \%$ of the expected blood volume. However, after a variable time lapse, rebleeding often occurred; the number and intensity of these events determined the total blood loss and soon appeared to be a key factor promoting mortality.

\section{Effect of arterial pressure}

Susan Stern's research team used the aortic tear model to study the effect of the arterial pressure on mortality. ${ }^{6}$ Swine were bled from one femoral artery to a mean arterial pressure (MAP) of $30 \mathrm{mmHg}$ after which the surgical steel aortotomy was induced. Fluid resuscitation with crystalloid fluid at a rate of $6 \mathrm{ml} / \mathrm{kg} / \mathrm{min}$ maintained a MAP of $40 \mathrm{mmHg}$ or $80 \mathrm{mmHg}$. The mortality was $13 \%$ and $63 \%$, respectively, in these two groups, while $88 \%$ of the animals died when no fluid was infused. A 5-fold larger 
intraperitoneal hemorrhage accompanied the higher mortality for the highest target MAP. This study showed that fluid resuscitation targeting a high MAP increased the mortality by accelerating the hemorrhage, while no fluid therapy at all also increased the mortality.

The same investigators also studied the effect of a more gradual increase in MAP on mortality, using the same controlled pre-bleed from the femoral artery before inducing the aortic tear. ${ }^{7}$ The MAP was raised to 40,60 , and $80 \mathrm{mmHg}$ by normal saline infused at $6 \mathrm{ml} / \mathrm{kg} / \mathrm{min}$, which was later changed to blood transfusions. The mortality was $11 \%, 22 \%$, and $78 \%$, respectively. These figures corresponded to a progressive increase of the intraperitoneal hemorrhage volume, which was measured after the animals had been sacrificed. Hence, mortality was still very low when the MAP was maintained at $60 \mathrm{mmHg}$, while an abrupt increase in mortality occurred when the MAP was raised to $80 \mathrm{mmHg}$.

Sondeen et al. ${ }^{8}$ used suction of the abdominal cavity to determine the pressure at which rebleeding occurs. They found that MAP averaged $64 \mathrm{mmHg}$ (systolic 94 and diastolic $45 \mathrm{mmHg}$ ) when rebleeding started. However, the pressure ranges were wide; for example, MAP at the onset of rebleeding varied between 30 to $90 \mathrm{mmHg}$.

\section{Varying the infused volume}

Using the aortic tear model, Bickell et al. studied the effects of infusing 3 times as much lactated Ringer's solution as the expected hemorrhage amount (3:1) over 10 min once the wire was pulled. ${ }^{9}$ Hemodynamic indices dropped markedly when the hemorrhage began, with transient improvement in response to fluid. All 8 pigs that received intravenous fluid died between 30 and $90 \mathrm{~min}$ after the infliction of the aortic laceration. In contrast, all 8 pigs that did not receive any fluid survived up to $120 \mathrm{~min}$, when the experiment ended. Hemodynamic indices dropped markedly when the hemorrhage began, with transient improvement in response to fluid. One difference from the studies performed by Stern and Riddez was that Bickell's animals were larger, 23-40 kg versus $15-20 \mathrm{~kg}$, which made the aortotomy relatively smaller in size. Moreover, the rate of infusion was higher.

In 32 of the smaller-sized pigs, Riddez and co-workers provided crystalloid fluid at a much lower rate. ${ }^{2}$ The infusions were administered in volumes of $0: 1,1: 1,2: 1$, and 3:1 times the (here, the expected) hemorrhage per hour. The low rate of infusion of 
Ringer's solution did not affect MAP but slightly increased blood flow rates in the aorta, portal vein, and left renal artery. The mortality at 2 hours was $25 \%$ in the $1: 1$ and 2:1 fluid groups, while being twice as high (50\%) in the $0: 1$ and $3: 1$ groups.

A marked reduction of oxygen consumption appearing within the first 10 minutes predicted a poor outcome. Only four animals that developed severe early oxygen debts survived up to 2 hours, and in them, either the 1:1 or the $2: 1$ fluid program caused a gradual normalization of oxygen consumption. In no other animal was an early severe oxygen debt reversible, which resulted in progressive acidosis and death.

These results corroborated that infusion fluid should be provided in uncontrolled hemorrhage situations but at a lower rate and at lower volumes than indicated by the widespread practice of infusing $3 \mathrm{ml}$ of Ringer's for each $1 \mathrm{ml}$ of blood lost (3:1 rule).

The same group also infused Ringer's acetate in the proportion 1:1 to the hemorrhage, but only over $20 \mathrm{~min}^{5}$ Hence, the infusion was provided at a rate corresponding to 3:1 per hour, but stopped much earlier. The results showed that rebleeding events occurred only during the period of time when fluid was infused. The fluid did not reverse the oxygen debt that developed early after the initial hemorrhage, and $50 \%$ of the animals subsequently died.

This study illustrated the danger of infusing fluid at a high rate rather than providing a large volume. Based on the previous work, one would expect $25 \%$ mortality to result from the infused volume, but instead, the figure found corresponded to that obtained by using the same infusion rate. ${ }^{2}$ It also became even more evident that the earliest studies using the aortic tear model ${ }^{6,7,9}$ had infused crystalloid fluid much too fast to promote survival.

\section{Hypertonic saline in dextran}

Seven and one half percent saline in 6\% dextran 70 (HSD) is a resuscitation fluid with a high potency to increase plasma volume. In humans, HSD is seven times more efficient than normal saline as a plasma volume expander ${ }^{10}$ and reverses evidence of hypovolemia very quickly in controlled hemorrhage models. ${ }^{11}$ Several clinical trials have used this fluid in pre-hospital settings. ${ }^{12,13}$ Therefore, it was of interest to test HSD in the aortic tear model.

Bickell, Bruttig \& Wade randomized 24 pigs to receive no fluid, $80 \mathrm{ml} / \mathrm{kg}$ of lactated Ringer's over $9 \mathrm{~min}$, or $4 \mathrm{ml} / \mathrm{kg}$ of HSD over $1 \mathrm{~min} .{ }^{14}$ All the control animals 
survived and all the Ringer animals died. The investigators found that HSD increased the hemorrhage but not as much as Ringer's did. At $120 \mathrm{~min}$, the mortality was $60 \%$. As before, the pigs were larger than the ones used by Stern and Riddez, which meant that the $5 \mathrm{~mm}$ aortotomy was a less serious injury and did not necessitate fluid therapy. Halothane was used for anesthesia while Riddez used ketamine, of which the latter largely retains the cardiovascular responses typical of conscious animals.

Riddez' group performed a study comparing the outcomes of injecting HSD in the recommended dose of $4 \mathrm{ml} / \mathrm{kg}$ to the outcomes with $2 / 3$ of the recommended dose injected over 1 min. $^{15}$ The treatments rapidly restored both the aortic and splanchnic blood flows to pre-bleeding levels but less dramatically increased MAP (peak 70 $\mathrm{mmHg}$ ). These changes were associated with re-bleeding in $80 \%$ of the pigs (Fig. 3 ). Sixty percent of the animals died. These results showed that effective restoration of flow parameters is not associated with good survival in this type of hemorrhage.

A later study investigated whether a slower $(5 \mathrm{~min})$ administration of 1 and 2 $\mathrm{ml} / \mathrm{kg}$ of HSD would be better tolerated than the $4 \mathrm{ml} / \mathrm{kg}$ dose. ${ }^{16}$ The smallest volume was followed by $20 \%$ mortality while both the larger ones were associated with a mortality of $50 \%$. The initial hemorrhage from the laceration was quite similar in the groups (approximately $400 \mathrm{ml}$ in pigs weighing $21 \mathrm{~kg}$ ), and for the most part, the animals that rebled died. Logistic regression showed that both the choice of fluid volume and the decrease in oxygen consumption after the initial hemorrhage served as predictors of death.

These three studies illustrate that HSD is dangerous to inject rapidly in the recommended dose $(4 \mathrm{ml} / \mathrm{kg})$ when there is uncontrolled hemorrhage. To promote survival, a lower dose should be chosen and the injection time should be extended. As with Ringer's, ${ }^{2}$ dramatic increases in blood flow rates and rebleeding could occur without MAP being markedly changed, if at all.

\section{Starch}

Acetated or lactated Ringer's solution and HSD have long been the traditional fluids used for resuscitation in pig models of uncontrolled hemorrhage. There are scattered data on hydroxyethylstarch but no series of studies using a standardized model in which the infused volume has been varied to identify an increment that optimizes survival.

Zaar et al. ${ }^{17}$ used liver damage in $30-\mathrm{kg}$ pigs which caused a moderately large 
(200 ml) initial hemorrhage. The animals were randomized to two phases of fluid administration with equal volumes of Ringer's lactate or hydroxyethyl starch (unknown brand). The results show that Ringer's did not markedly aggravate the bleeding while it was increased 10-foldt from rebleeding induced by the starch.

Alam et $a{ }^{18}{ }^{18}$ subjected pigs to femur fracture, controlled hemorrhage, and finally to liver damage. In this complex model resuscitation with $6 \%$ hetastarch (MW $600 \mathrm{kD}$, Hextend) resulted in 85\% mortality while fresh whole blood, fresh frozen plasma with and without red blood cells in the ratio $1: 1$ were followed by $100 \%$ survival. Coagulopathy worsened after hetastarch but was reversed by all blood-based treatments.

\section{STUDIES IN RATS}

Experimental models of uncontrolled hemorrhage in rats include cutting of internal organs and blood vessels. Most widely used is the "cut tail" or "tail amputation" model which is even somewhat older than the aortic tear model.

\section{Effect of arterial pressure}

Tao Li et al. from China created uncontrolled hemorrhage by transecting the spleen and one branch of the splenic artery. ${ }^{19,20}$ Using barbital anesthesia, their key findings with intra-abdominal hemorrhage are consistent with those found with the aortic tear model in the pig. Hence, the survival was highest when MAP was kept low (50 $\mathrm{mmHg}$, while $100 \mathrm{mmHg}$ is normal). A higher MAP was also associated with a progressive increase of hemorrhage volume. ${ }^{19}$ In a follow-up study, Li showed that a slightly higher MAP (70 $\mathrm{mmHg}$ ) is optimal after the hemorrhage has been arrested surgically. ${ }^{20}$

\section{Anesthesia and fluid volume}

By using a model of splenic injury, Abu-Hatoum et al. ${ }^{21}$ confirmed that the blood loss and the mortality increases with the amount of crystalloid fluid used for resuscitation.

Soucy, Greene, and Shires explored the "cut tail model" in a series of experiments in the 1990s which yielded results slightly different from those obtained by 
the aortic tear model. ${ }^{22-24}$ Here, the choice of anesthesia appeared to have an impact on outcome. Ketamine, which retains vasoconstrictive responses, was associated with the highest mortality and the hypotensive anesthetic pentobarbital, which induces vasodilatation, with the lowest. ${ }^{22}$

The group then studied conscious rats, as they hypothesized that the detrimental effects of infusion fluids found in experimental models is due to the anesthesia. Under such conditions, a larger resuscitation volume of normal saline ( 80 $\mathrm{ml} / \mathrm{kg}$ ) was followed by less hemorrhage and lower mortality $(24 \%)$ than a smaller fluid volume $(40 \mathrm{ml} / \mathrm{kg}$ ) and no resuscitation (mortality rates were 71 and $76 \%$, respectively). ${ }^{23}$ The saline was infused over only 4 min starting 15 min after cutting the tail, and it did not seem to initiate rebleeding. ${ }^{23}$ Hence, the largest fluid volume promoted survival.

A later study under, which was performed under ether anesthesia, compared an infusion of normal saline in a "moderate" volume of $80 \mathrm{ml} / \mathrm{kg}$ with a large volume of $283 \mathrm{ml} / \mathrm{kg}$. Each volume group also had an arm where the fluid was infused at a low rate $(3.3 \mathrm{ml} / \mathrm{kg} / \mathrm{min})$ and a high rate $(17.8 \mathrm{ml} / \mathrm{kg} / \mathrm{min})$. The results showed that the rate of the hemorrhage increased with the amount of infused fluid and inversely with the rate, which is opposite to the findings with the aortic tear model. Hence, the fast infusion of the "moderate" volume was associated with the lowest mortality $(40 \%)$ while no resuscitation resulted in a mortality of $83 \%{ }^{24}$ Surprisingly, the hemorrhage volume in the group with the poorest outcome was only $8 \mathrm{ml} / \mathrm{kg}$, which would not cause death in pigs or humans.

\section{Colloids and blood products}

Data on the effects of colloids and blood products in rats subjected to uncontrolled hemorrhage models begin to assemble. However, the results are difficult to interpret due to small study groups and different set-ups.

In a splenic injury model, $7.5 \mathrm{ml} / \mathrm{kg} / \mathrm{h}$ of 6\% HAES-steril (MW $200 \mathrm{kD}$ ) prolonged survival, but the mortality after 4 hours was still the same (75\%) as for no resuscitation and for the maximum volume of Ringer's lactate $(105 \mathrm{ml} / \mathrm{kg} / \mathrm{h}){ }^{21}$ The only treatment that decreased the mortality was low-volume Ringer's lactate $(35 \mathrm{ml} / \mathrm{kg})$.

Li et $a .^{20}$ reported the better survival after splenic injury was obtained when resuscitation was performed either with a mixture of $2 / 3$ of Ringer's lactate and either 
1/3 of hydroxyethyl starch (MW $130 \mathrm{kD}$ ) or whole blood as compared to when Ringer's acetate alone or hydroxyethyl starch alone was administered.

Using a liver injury model, Letourneauy et $a l^{25}$ found that resuscitation with fresh thawed plasma after hemodilution was followed by $100 \%$ survival, while rats receiving thawed plasma stored for up to 5 days resulted in survival in only $54 \%$. As all sham animals also survived, plasma appeared to exert a negative influence on survival after being stored for only a few days.

Oxygen carriers ("artificial blood") have been tested in many studies of both controlled and uncontrolled hemorrhage in pigs and rats. There is some evidence that animals receiving oxygen carriers live longer. However, none of these blood substitutes is yet generally available for clinical use.

Studies of oxygen carriers are generally hampered by lack of kinetic-derived volume matching between the oxygen carrier and the fluid used for comparison. The degree of plasma volume expansion over time is crucial to both the hemodilution and the rebleeding which, in turn, affect the oxygen transport. Improved oxygen transport and ultimately survival attributable to the oxygen carrying capacity of the fluid is difficult to demonstrate in such a complex setting.

\section{Body temperature}

The Swedish surgeon Göran Heinius found that no hemorrhage occurs when amputating the tail of a rat under hypothermic conditions. He modified the preparation by exposing the femoral artery in the groin by surgical dissection and puncturing the vessel with a $0.5 \mathrm{~mm}$ disposable needle. Studies under ketamine/midazolam anesthesia targeted resuscitation at out-of-hospital events in a cold climate. Rats were cooled to $30^{\circ} \mathrm{C}$ and subjected to hemorrhagic shock.

During fluid resuscitation, rebleeding events became more frequent, had longer durations, and contained more blood in hypothermic animals as compared to normothermic animals. ${ }^{26}$ When comparing the outcomes for various fluid programs during hypothermia, the results still supported those obtained by the cut tail cut model mortality tended to be lower in large- and moderate-volume resuscitation with Ringer's acetate solution compared to small-volume resuscitation, despite the fact that the rebleeding volume increased with the infused volume. ${ }^{27}$

Hypothermia is well known to provoke coagulopathy. In white rabbits 
subjected to mild hypothermia $\left(35^{\circ} \mathrm{C}\right)$ followed by uncontrolled splenic injury, the tendency to develop coagulopathy was greater with hetastarch (MW 600 kD, Hextend) and dextran 70 compared to $5 \%$ human albumin. ${ }^{28}$ Mortality rates were $100 \%$ after resuscitation with hetastarch, $75 \%$ after dextran, and $50 \%$ after albumin.

\section{PATHOPHYSIOLOGY}

Experimental studies in animals have been the key source to our understanding of the balance between beneficial and adverse effects of fluid infusion in uncontrolled hemorrhage. Injury to a large blood vessel results in the formation of a thrombus that adheres to the outer surface of the vessel and the surrounding tissue. ${ }^{29,30}$ In pigs, this immature clot arrests the hemorrhage within $4 \mathrm{~min}$ in the aorta, ${ }^{4,5,15,16}$ while liver injury might require twice as long time. ${ }^{31}$ However, mechanical and chemical forces can apparently disturb stabilization of the clot.

A rise in the arterial pressure dilates the vessels and might wash away the thrombus by sheer force, which initiates rebleeding both in the aortic tear model ${ }^{6,7}$ and in the femoral artery model ${ }^{32,33}$ of swine. Monitoring of rebleeding events by the double flow probe method shows that an increase in blood flow rate, which increases the kinetic energy, ${ }^{34}$ is a more sensitive marker of rebleeding than MAP.

For example, cardiac output increased by $60 \%$ during the 10 min just prior to a major rebleeding event in 4 pigs, and cardiac output was already above baseline in a fifth animal. At the same time the aortic blood flow increased by $40 \%$ on the average. In contrast, the systolic arterial pressure rose by only $2 \mathrm{mmHg}$ (to $58 \mathrm{mmHg}$ ) and MAP remained unchanged $\left(32 \mathrm{mmHg}\right.$, unpublished). ${ }^{2}$

Hence, an increase in blood flow typically precedes a rebleeding event, which suddenly reduces the resistance to flow, and thereby, further but transiently increases the flow rate ${ }^{16}$ (Fig. 3). When a new clot forms, the blood flow rate again decreases. Hence, the blood flow in a vessel and the hemorrhage exhibit a timely interplay. Another factor that might contribute to rebleeding is the reduced viscosity that results from the hemodilution induced by infusion fluids.

The incidence of rebleeding is very low when crystalloid fluid therapy is not actively performed. On the other hand, some fluid should apparently be infused to 
prevent hypovolemic shock, ${ }^{2,22}$ recognizing that vigorous fluid administration is detrimental in the intra-abdominal hemorrhage, both when resuscitation is performed with isotonic ${ }^{9,19}$ or hypertonic fluid. ${ }^{14-16}$ In contrast, vigorous fluid administration (80 $\mathrm{ml} / \mathrm{kg}$ ) promotes survival in the cut tail model, which represents a more peripheral vascular injury, although the hemorrhage volume might be larger. ${ }^{22-24}$

Ambitious fluid therapy may not be as deleterious in uncontrolled hemorrhage from parenchymal organs. For example, in a model of liver injury in the rat, hypertonic saline maintained circulating blood volume and survival despite increased hemorrhage. ${ }^{35}$ In the pig, administration of $4 \mathrm{ml} / \mathrm{kg}$ of HSD did not induce rebleeding from a liver injury. ${ }^{31}$ However, uncontrolled hemorrhage from parenchymal organs has been less intensively studied than direct injuries to major blood vessels.

\section{IMPLICATIONS FOR TREATMENT}

\section{Clinical studies}

The ultimate treatment of major hemorrhage is surgical, but in anesthesia and trauma care there is a reflex behavior based on the belief that fluid should be infused to "buy time" before irreversible shock develops. The possibility that uncontrolled hemorrhage from a major blood vessel might be present makes this therapy potentially dangerous. The prevalence of the uncontrolled type of hemorrhage in pre-hospital settings is unknown, but one author estimated the incidence to be $25 \%$ of blunt traumas to the chest, abdomen, or pelvis. ${ }^{36}$ In penetrating trauma, the incidence is probably higher.

In a classical study of pre-hospital penetrating injuries, Bickell and co-workers in 1994 compared the outcomes of 598 hypotensive patients half of which received infusion fluid on the scene of an accident while the other half received fluid only after having entered the operating room. ${ }^{37}$ The immediate-resuscitation group received $2.5 \mathrm{~L}$ of fluid and the delayed resuscitation group only $350 \mathrm{ml}$ before entering surgery. The results showed a slight but statistically significant increased survival rate in the delayed resuscitation group (70\% versus 62\%). Differences were greater in the most severely 
injured patients (61\% versus $48 \%)$. This study appears to support the "scoop-and-run" strategy in hypotensive trauma patients in large cities when the transport time to hospital is no longer than 20-30 min. In rural areas, where transport time exceeds 30 min, hypovolemic shock should probably be treated with infusion fluids on the scene of the accident and during transport to hospital.

The value of HSD in the pre-hospital setting has been the subject of many studies. Eight clinical trials in the 1980s and 1990s failed to show an effect on survival. A meta-analysis based on 6 of the 8 trials still showed a mortality rate of $23.8 \%$ in those patients treated with isotonic fluid and $17.3 \%$ in those who received HSD as a first treatment, a difference that was statistically significant. ${ }^{12,38}$

The Canadian surgeon Eileen Bulger has more recently re-assessed HSD in several clinical trials comprising over 800 patients. She found that neither mortality nor the neurological outcome in trauma victims differed between the administration of HSD, 7.5\% saline, and the use of normal saline, which was the standard of care. ${ }^{13,39}$ However, the dose of HSD in the study was $250 \mathrm{ml}$, which corresponded to the $4 \mathrm{ml} / \mathrm{kg}$ shown to be detrimental in the aortic tear model. ${ }^{14-16}$ Hence, the fluid therapy might have brought the patients from lower to the upper part of the U shaped mortality versus amount of fluid curve, then passing the increment where survival is optimal.

Some encouraging results with hydroxyethyl starch as first-line treatment in trauma have been reported ${ }^{40,41}$ while a colloid/crystalloid ratio $>2$ seems to promote coagulopathy. ${ }^{42}$ A problem is that most studies involving starch use hetastarch (MW 600 $\mathrm{kD}$, Hextend) which has very limited role in European medical care.

\section{Hemostatic dressings and drugs}

Animal studies of uncontrolled hemorrhage have recently focused on ways to decrease and control the bleed volume with mechanical devices and hemostatic drugs. For example, the femoral artery in pigs has been used to study the patency of wound dressings to withstand increasing arterial pressures. ${ }^{32,33,43}$

Tranexamic acid, which inhibits fibrinolysis, had no effect on the amount of blood lost in the aortic tear model in the pig when administered between the time of the initial hemorrhage and the initiation of fluid resuscitation. ${ }^{44}$ Other studies have dealt with desmopressin, which increases the concentration of the von Willebrand factor and coagulation factor VIII and improves platelet adhesion to injured endothelium. An 
aortic tear model in rabbits showed that both permissive hypotension and desmopressin augments clot formation; however, the desmopressin was then administered 1 hour before hypovolemic shock was induced. ${ }^{45}$ In the cut tail model of the rat, neither tranexamic acid nor desmopressin had such an effect when given approximately 5 min before hemorrhage was induced. ${ }^{46}$ In addition, desmopressin did not alleviate hemorrhage in the femoral artery model of hypothermic rats; here, the drug was injected 5 min after hypovolemic hypotension had been induced. ${ }^{27}$

Recombinant-activated factor VII (rFVIIa; NovoSeven) has received the greatest attention among the hemostatic drugs. Several animal studies and smaller clinical trials of this procoagulant therapy have been published in the past decade. ${ }^{47}$ However, these studies do not challenge fluid therapy and, therefore, are outside the scope of this review.

\section{Volume kinetic analyses}

Computer simulations based on volume kinetic data derived from humans corroborate many experiences from animal experiments. Such simulations show that the resuscitation strategies practiced for decades are likely to boost the blood flow rates by increasing the blood volume to supramaximal levels, thereby promoting rebleeding.

Crystalloid fluids. An often overlooked fact is that distribution of crystalloid fluid from the intra- to the extravascular space is not immediate. The distribution halflife averages 8 min, which makes Ringer's solution a more effective plasma volume expander than commonly believed as long as the fluid is infused and for 20-30 min thereafter ${ }^{48}$ (Fig. 4).

Simulations based on data from Drobin \& $\mathrm{Hahn}^{49}$ illustrate the summary effect of distribution and capillary refill on the plasma volume expansion in normotensive adult male volunteers who had $900 \mathrm{ml}$ of blood removed within 10-15 min (controlled hemorrhage). Here, the practice of infusing 3 times the hemorrhage volume with Ringer's solution (3:1 rule) over 30 minutes is shown to create marked hypervolemia (Fig. 5A). The infusion volume required to restore normovolemia is rather $1.5 \mathrm{~L}$ (1.6 times the bled volume) if fluid resuscitation starts immediately after the hemorrhage. The required volume will be only $1.0 \mathrm{~L}$ if the infusion is initiated with a delay of $45 \mathrm{~min}$ (Fig. 5B).

A nomogram, depicting the infusion rates and infusion times required to restore 
the blood volume after hemorrhage of 450 and $900 \mathrm{ml}$, is shown in Fig. 6. Isobars also indicate how deliberate hypovolemia $(-300 \mathrm{ml})$, which appears to be justified to prevent both shock and rebleeding, can be achieved. The nomogram is based on a time lapse of $30 \mathrm{~min}$ between the hemorrhage and the initiation of fluid resuscitation, which is representative for many pre-hospital scenarios.

If bleeding continues, further computer simulation yields that the requirement for maintaining deliberate hypovolemia $(-300 \mathrm{ml})$ is to infuse 1.6 times the continuously bled volume with Ringer's acetate, which must be increased to 2.0 times the bled volume if normovolemia is desired. These ratios probably become altered with time as the intravascular space gradually becomes depleted of proteins. Data for further simulation is not available, but blood products become critically needed to prevent coagulopathy and to maintain oxygen delivery when approximately one blood volume has been replaced in this way. If available, they should naturally be transfused at much earlier stage of a serious hemorrhage episode.

Another volunteer study confirms that infusing $900 \mathrm{ml}$ of Ringer's after withdrawal of $900 \mathrm{ml}$ of blood creates a slightly hypokinetic circulation, while $1800 \mathrm{ml}$ is followed by a clear hyperkinetic circulation with increased lung water. ${ }^{50}$ The authors concluded that optimal volume substitution with Ringer's is obtained by infusing between $100 \%$ and $200 \%$ of the blood lost.

Studies in humans undergoing surgery ${ }^{51}$ and bled pigs ${ }^{17}$ also support that the immediate plasma volume expansion from Ringer's solution is $60-75 \%$ of the infused volume, which is much greater than proposed in medical textbooks.

Little is known about the disposition of infusion fluids in hypovolemic hypotensive states. Retrospective analysis of animals without rebleeding from two pig studies $^{2,5}$ suggest that the fluid efficiency of Ringer's acetate solution over 20, 30 and 50 minutes is similar to those shown for normotensive humans in Figure 5 (for calculations, see Appendix). An exception might be that the distribution could occur more slowly during onset of the hypotension, as is the case during induction of anesthesia. $^{48}$

Hypertonic and colloid fluids. Volume kinetic studies of HSD have only been performed in normovolemic volunteers ${ }^{10}$ and sheep. ${ }^{52}$ Hypervolemia of at least $400 \mathrm{ml}$ can be expected if $250 \mathrm{ml}$ (approximately $4 \mathrm{ml} / \mathrm{kg}$ ) of HSD is infused over $10 \mathrm{~min}$ after a hemorrhage of $900 \mathrm{ml}$ (simulation not shown). The dose of HSD that fully restores the 
blood volume is rather $150 \mathrm{ml}$ (approximately $2 \mathrm{ml} / \mathrm{kg}$ ) than $250 \mathrm{ml}$. Retrospective analysis of 11 pigs with hypovolemic hypotension but without rebleeding ${ }^{16}$ indicates that a low MAP does not markedly change the efficiency of HSD to expand the plasma volume.

There are no volume kinetic data on isotonic colloid fluids or blood products in hypovolemic states that allow construction of infusion rate/time-plots, as is possible for Ringer's acetate (Fig. 6). Moreover, the existing studies have not varied the infusion volume or infusion rate in a way that allows us to even extrapolate a dosage that would prevent shock but still avoid rebleeding. Such data would be very helpful for those who wish to manage uncontrolled hemorrhage with fluids other than Ringer's or HSD.

This issue might still be less crucial for colloids than for crystalloids as these fluids lack a prominent distribution phase. ${ }^{48}$ There is reason to believe that less volume should be infused in uncontrolled hemorrhage than commonly believed, as catecholamine secretion and capillary refill in response to the hemorrhage promote a hyperkinetic circulation and partly restore the blood volume.

Scattered experimental evidence support this view. For example, infusion of $900 \mathrm{ml}$ of $5 \%$ albumin after withdrawal of $900 \mathrm{ml}$ of blood in volunteers increased cardiac output to $400 \mathrm{ml} / \mathrm{min}$ and the blood volume to $200 \mathrm{ml}$ above baseline ${ }^{50}$ while $5 \%$ albumin is known to expand the plasma volume by $80 \%$ of the infused amount in normovolemic volunteers. ${ }^{53}$

\section{Rational basis of treatment}

The experience from studies in pigs and most data from rats, the exception being those derived by the cut tail model, show that a normal arterial pressure and high blood flow rates should be avoided. The arterial pressure can be monitored while the blood flow in a major vessel is more difficult to assess. However, high flow rates are primarily a consequence of the intravenous fluid therapy. Our best way to avoid them is currently to adopt a well-tailored fluid therapy program.

The clinically adopted rule is to avoid restoring MAP to normal levels. A current guideline suggests that target MAP that assures optimal survival probably is 65$75 \mathrm{mmHg}$ (systolic pressure 80-100). ${ }^{54}$ A recommendation of a MAP of $60 \mathrm{mmHg}$ has previously been given based on data from pigs. ${ }^{8}$ Such "permissive resuscitation" includes restrictive fluid therapy, with the possible addition of vasoconstrictive drugs in 
case MAP is too low to permit essential tissue perfusion. Unfortunately, the benefit of permissive resuscitation has not been convincingly demonstrated in human trauma situations. In any event, the practice should be abandoned to secure cerebral perfusion in case of concomitant head trauma.

Restoration of blood flow rates by infusion fluids should avoid hypervolemia. As already shown, replacing blood loss by 3 times the volume by Ringer's or $250 \mathrm{ml}$ of HSD causes hypervolemia in volunteer experiments and might be deleterious when there is a risk of rebleeding. Volume kinetics also suggests that bolus infusions of crystalloid fluid should not be used, as the distribution effect will create marked but transient changes in blood volume (Fig. 4). An oscillating pattern of blood volume changes is less likely to occur from HSD or colloid boluses, as these fluids lack distribution function. ${ }^{48}$

The effects of the resuscitation with fluid and drugs should be observed closely. ${ }^{55}$ Animal experiments hold that a typical sign of rebleeding is a sudden drop in arterial pressure when fluid administration is considered adequate. If this occurs the intensity of the fluid resuscitation should be reduced, not increased. A risk with using the "target MAP" strategy is that more fluid would be infused in such a situation, which will only aggravate the rebleeding problem. In addition to the arterial pressure, patient monitoring includes plasma lactate and acid-base balance. ${ }^{54}$ Arterial samples are preferred. Progressive acidosis indicates bad prognosis. ${ }^{2,15}$ A low oxygen consumption precedes the development of acidosis, but this measurement is not clinically available.

What volumes and infusion rates can then be recommended? No absolute truth can yet be presented, although we are aware of what should be avoided. The amount of blood lost is usually unknown, but one may take a blood loss of 1,000 $\mathrm{ml}$ as an initial assumption when hemorrhage has resulted in arterial hypotension in an adult man. The starting volume of Ringer's could well be $600-750 \mathrm{ml}$ over $20-30 \mathrm{~min}$, after which the patient would still be somewhat hypovolemic (Fig. 6). Both animal experiments and kinetic simulations suggest that a reasonably safe initial fluid resuscitation with HSD should consist of $100 \mathrm{ml}$ over 5-10 minutes. Extending the infusion time to $20 \mathrm{~min}$ is likely to further increase the safety of this treatment.

These implications given above should not be regarded as clinical guidelines but as rational conclusions based on the experiments referred to in this review.

Colloid fluids still have a limited place for first-line resuscitation in trauma. ${ }^{58}$ 
Fresh whole blood and plasma are most likely superior to clear fluids, ${ }^{55}$ provided that they are not given in amounts large enough to cause rebleeding. However, logistic problems rarely make blood-based fluids available before the patient reaches a trauma center or university hospital. At that time, uncontrolled hemorrhage can be diagnosed by surgical exploration or invasive radiology. Definite treatment is surgical.

Many recent studies deal with retrospective analyses of survival depending on how various blood products have been combined. These studies, which are boosted by experiences from the wars in Iraq and Afghanistan, associate improved outcome with earlier use of plasma and platelets. ${ }^{59}$ However, these exciting topics, as well as many other in essential components of trauma care, fall outside this review.

\section{CONCLUSIONS}

Uncontrolled hemorrhage occurs from damage to major blood vessels. The bleeding stops spontaneously when blood flow rates and MAP decrease as part of hypovolemic shock. Experimental studies in animals demonstrate that stabilization of the clot can be disturbed by a rise in blood flow rate and/or MAP. Such changes promote rebleeding, which markedly increases the size of the total hemorrhage as well as the resulting mortality. Rebleeding events become more frequent and longer when complicated by hypothermia, which gives rise to both vasoconstriction and coagulopathy. Rebleeding probably becomes less of an issue in distal vascular injuries.

To avoid rebleeding and to assure optimal survival, a resuscitation program that does not aim to restore normal MAP ("permissive hypotension") should be used. A rise in blood flow rate augmented by an increased blood volume appears to be an earlier sign of improved hemodynamics than MAP. The blood flow rate is primarily governed by the plasma volume expansion caused by intravenous fluid.

The mortality versus the amount of fluid curve shows a U shaped curve with higher mortality at either end. No fluid at all allows hypovolemic shock to become manifest and too much fluid promotes further exsanguination. Unfortunately, traditional clinical rules of volume replacement tend to place patients on the upper part of the Ushaped mortality curve. Animal experiments and computer simulations based on fluid volume kinetics suggest that initial fluid resuscitation in a hypotensive patient may 
consist of 600-750 $\mathrm{ml}$ of crystalloid fluid or $100 \mathrm{ml}$ of HSD. Fluid and drugs should be titrated and the effects be observed closely.

There is considerable difficulty in making the diagnosis of rebleeding, especially under pre-hospital conditions, but a typical sign is a sudden drop in arterial pressure when fluid administration is considered adequate.

\section{REFERENCES}

1. Bickell WH, Bruttig SP, Wade CE. Hemodynamic response to abdominal aortotomy in the anesthetized swine. Circ Shock 1989; 28: 321-32.

2. Riddez L, Johnsson L, Hahn RG. Central and regional hemodynamics during fluid therapy after uncontrolled intra-abdominal bleeding. J Trauma 1998; 44: 433-9.

3. Kösterling K, Mast W-P, Kaethner T, Nebendahl K, Holtz WH. Blood coagulation studies in domestic pigs (Hanover breed) and minipigs (Goettingen breed). Lab Animals 1983; 17: 346-9.

4. Riddez L, Johnsson L, Hahn RG. Early hemodynamic changes during uncontrolled intra-abdominal bleeding. Eur Surg Res 1999; 31: 19-25.

5. Riddez L, Hjelmqvist H, Suneson A, Hahn RG. Short-term crystalloid fluid resuscitation in uncontrolled intra-abdominal bleeding in swine. Prehosp \& Disaster Med 1999; 14: 87-92.

6. Kowalenko T, Stern S, Dronen S, Wang X. Improved outcome with hypotensive resuscitation of uncontrolled hemorrhagic shock in a swine model. J Trauma 1992; 33: 349-53.

7. Stern SA, Dronen SC, Birrer P, Wang X. Effect of blood pressure on hemorrhage volume and survival in a near-fatal hemorrhage model incorporating a vascular injury. Ann Emerg Med 1993; 22: 155-63.

8. Sondeen JL, Coppes VG, Holcomb JB. Blood pressure at which rebleeding occurs after resuscitation in swine with aortic injury. J Trauma 2003; 54: S110-7.

9. Bickell WH, Bruttig SP, Millnamow GA, O’Benar J, Wade CE. The detrimental effects of intravenous crystalloid after aortotomy in swine. Surgery 1991; 110: 529-36. 
10. Drobin D, Hahn RG. Kinetics of isotonic and hypertonic plasma volume expanders. Anesthesiology 2002: 96: 1371-80.

11. Maningas PA, DeGuzman LR, Tillman FJ, Hinson CS, Priegnitz KJ, Volk KA, Bellamy RF. Small volume infusion of $7.5 \% \mathrm{NaCl}$ in $6 \%$ dextran-70 for treatment of severe hemorrhagic shock in swine. Ann Emerg Med 1986; 15: 1131-7.

12. Wade CE, Kramer GC, Grady JJ, Fabian TC, Younes RN. Efficacy of hypertonic $7.5 \%$ saline and $6 \%$ dextran-70 in treating trauma: a meta-analysis of controlled clinical studies. Surgery 1997; 122: 609-16.

13. Bulger EM, May S, Kerby JD, Emerson S, Stiell IG, Schrieber MA, Brasel KJ, Tisherman SA, Coimbra R, Rizoli S, Minei JP, Hata JS, Sopko G, Evans DC, Hoyt DB; ROC Investigators. Out-of-hospital hypertonic resuscitation following traumatic hypovolemic shock: a randomized, placebo-controlled trial. Ann Surg $2011 ; 253: 431-41$.

14. Bickell WH, Bruttig SP, Millnamow GA, O’Benar J, Wade CE. Use of hypertonic saline/dextran versus lactated Ringer's solution as a resuscitation fluid after uncontrolled aortic hemorrhage in anesthetized swine. Ann Emerg Med 1992; 21: 1077-85.

15. Riddez L, Hahn RG, Suneson A, Hjelmqvist H. Central and regional hemodynamics during uncontrolled bleeding using hypertonic saline dextran for resuscitation. Shock 1998: 10: 176-81.

16. Riddez L, Drobin D, Sjöstrand F, Svensén C, Hahn RG. Lower dose of hypertonic-saline dextran reduces the risk of lethal rebleeding in uncontrolled hemorrhage. Shock 2002: 17: 377-82.

17. Zaar M, Lauritzen B, Secher NH, Krantz T, Nielsen HB, Madsen PL, Johansson PI. Initial administration of hydroxyethyl starch $v s$ lactated Ringer after liver trauma in the pig. Br J Anaesth 2009; 102: 221-6.

18. Alam HB, Bice LM, Butt MU, Cho D, Dubick MA, Duggan M, Englehart MS, Holcomb JB, Morris MS, Prince D, Schreiber MA, Shults C, Sondeen JL, Tabbara M, Tieu BH Underwood SA; Hemostatic Resuscittaion Reesrcah Group. Testing blood products in a polytrauma model: results of a multi-institutional randomized preclinical trial. J Trauma 2009; 67: 856-64.

19. Li T, Zhu Y, Hu Y, Li L, Diao Y, Tang I, Liu L. Ideal permissive hypotension to resuscitate uncontrolled hemorrhagic shock and the tolerance time in rats. 
Anesthesiology 2011; 114: 111-9.

20. Li T, Zhu Y, Fang Y, Liu L. Determination of the optimal mean arterial pressure for postbleeding resuscitation after hemorrhagic shock in rats. Anesthesiology 2012; 116; 103-12.

21. Abu-Hatoum O, Bashenko Y, Hirsh M, Krausz MM. Continuous fluid resuscitation and splenectomy for treatment of uncontrolled hemorrhagic shock after massive splenic injury. J Trauma 2002; 52: 253-8.

22. Soucy DM, Sindlinger JF, Greene SP, Berber A, Illner H, Shires GT. Effects of anesthesia on a model of uncontrolled hemorrhage in rats. Crit Care Med 1995; 23:1528-32.

23. Greene SP, Soucy DM, Song WC, Barber AE, Hagedorn FN, Illner HP, Shires T. Early isotonic saline resuscitation from uncontrolled hemorrhage in rats. Surgery 1998; 124: 568-74.

24. Soucy DM, Rudé M, Hsia WC, Hagedorn FN, Illner H, Shires GT. The effects of varying fluid volume and rate of resuscitation during uncontrolled hemorrhage. J Trauma 1999; 46: 209-15.

25. Letourneau PA, McManus M, Sowards K, Wang W, Wang Y, Matiljevic N, Pati S, Wade CE, Holcomb JB. Aged plasma transfusion increases mortality in a rat model of uncontrolled hemorrhage. J Trauma 2011; 71: 1115-9.

26. Heinius G, Hahn RG, Sondén A. Hypothermia increases re-bleeding during uncontrolled hemorrhage in the rat. Shock 2011; 36: 60-6.

27. Heinius G, Sondén A, Hahn RG. Effects of different fluid regimes and desmopressin on uncontrolled hemorhage during hypotheria in the rat. Ther Hypotherm Temp Management 2012; in press.

28. Kehirabadi BS, Crissey JM, Deguzman R, Perez MR, Dubick MA, Holcomb JB. Effects of synthetic vereus natural colloid resuscitation on inducing dilutional coagulopathy and increasing hemorrhage in rabbits. J Trauma 2008; 64: 1218-28.

29. Shaftan GW, Chiu C-J, Dennis C, Harris B. Fundamentals of physiologic control of arterial hemorrhage. Surgery 1965; 58: 851-6.

30. Sixma JJ, Wester J. The hemostatic plug. Semin Hematol 1977; 14: 265-99.

31. Talving P, Riddez L. A pilot study on early versus delayed hypertonic saline dextran resuscitation in a porcine model of near-lethal liver injury. Early hemodynamic response and short-term survival. J Surg Res 2006; 136: 273-9. 
32. Burgert JM, Gegel BT, Austin R $3^{\text {rd }}$, Davila A, Deeds J, Hidges L, Hover A, Lockhart C, Roy J, Simpson G, Weaver S, Wolfe W, Johnson D. Effects of arterial pressure on rebleeding using Celox and TraumaDEX in a porcine model of lethal femoral injury. AANA J 2010; 78: 230-6.

33. HaYoung Hirst HY, Brinkman J, Beasley A, Crocker R, O'Sullivan J. The effects of blood pressure on rebleeding when using ExcelArrest ${ }^{\mathrm{TM}}$ in a porcine model of lethal femoral injury. J Emerg Trauma Shock 2011; 4: 207-11.

34. Wangenstein SL, Eddy DM, Ludwig RM. The hydrodynamics of arterial hemorrhage. Surgery 1968; 64: 912-21.

35. Matsouka T, Hildreth J, Wisner DH. Liver injury as a model of uncontrolled hemorrhagic shock: resuscitation with different hypertonic regimens. J Trauma 1995; 39: 674-80.

36. Lechleuter A, Lefering R, Bouillon B, Lentkje E, Vorweg M, Tiling T. Prehospital detection of uncontrolled haemorrhage in blunt trauma. Eur J Emerg Med 1994; 1: $1-13$.

37. Bickell WH, Wall MJ, Pepe PE, Martin RR, Ginger VF, Allen MK, Mattox KL. Immediate versus delayed resuscitation for hypotensive patients with penetrating torso injuries. N Engl J Med 1994; 331: 1105-9.

38. Kramer GC, Wade CE, Prough DS. Hypertonic saline dextran: Efficacy and regulatory approval. Acta Anaesthesiol Scand 1998: 42: 141-4.

39. Bulger EM, May S, Brasel KJ, Schreiber M, Kerby JD, Tisherman SA, Newgard C, Slutsky A, Coimbra R, Emerson S, Minei JP, Bardarson B, Kudenchuk P, Baker A, Christenson J, Idris A, Davis D, Fabian TC, Aufderheide TP, Callaway C, Williams C, Banek J, Vaillancourt C, van Heest R, Sopko G, Hata JS, Hoyt DB; ROC Investigators. Out-of-hospital hypertonic resuscitation following severe traumatic brain injury: a randomized controlled trial. JAMA 2010; 304: 1455-64.

40. James FM, Michell WL, Joubert IA, Nivol AJ, Navsaria PH, Gillespie RS. Resuscitation with hydroyxyethyl starch improves renal function and lactate clearance in penetrating trauma in a randomized controlled study: the FIRST trial (Fluids in Resuscitation of Severe Trauma). Br J Anaesth 2011; 107: 693-702.

41. Ogilvie MP, Pereira BMT, McKenney MG,McMahon PJ, Manning RJ, Namias N, Livingstone AS, Schulman CI, Proctor KG. First report on safety and efficacy of hetastarch solution for initial fluid resuscitation at a Level 1 trauma center. J Am 
Coll Surg 2010; 210: 870-80.

42. Wafaisade A, Wutzler S, Lefering R, Tjardes T, Benerjee M, Paffrath T, Bouillon B, Maegele M. Drivers of acute coagulopathy after severe trauma: a multivariate analysis of 1987 patients. Emerg Med J 2010; 22: 934-9.

43. Ward KR, Tiba MJ, Holbert WH, Blocher GT, Priffitt EK, Bowlin GL, Ivatury RR, Diegelmann RF. Comparison of a new hemostatic agent to current combat hemostatic agents in a Swine model of lethal extremity arterial hemorrhage. J Trauma 2007; 63: 276-83.

44. Drobin D, Sjöstrand F, Piros D, Hedin A, Heinius G, Hahn RG. Tranexamic acid does not prevent rebleeding in an uncontrolled hemorrhage porcine model. J Trauma 2005: 59: 976-83.

45. Rezende-Neto JB, Rizoli SB, Andrade MV, Ribeiro DD, Lisboa TA, Camargos ER, Martins P, Cunha-Melo JR. Permissive hypotension and desmopressin enhance clot formation. J Trauma 2010; 68: 42-51.

46. Ryan KL, Cortez DS, Dick EJ Jr., Pusateri AE. Efficacy of FDA-approved hemostatic drugs to improve survival and reduce bleeding in rat models of uncontrolled hemorrhage. Resuscitation 2006; 70: 133-44.

47. Dutton RP, Conti BM. The role of recombinant-activated factor VII in bleeding trauma patients. Curr Opin Anesthesiol 2009; 22: 299-304.

48. Hahn RG. Volume kinetics of infusion fluids (review). Anesthesiology 2010; 113: 470-481.

49. Drobin D, Hahn RG. Volume kinetics of Ringer's solution in hypovolemic volunteers. Anesthesiology 1999; 90: 81-91.

50. Riddez L, Hahn RG, Brismar B, Strandberg Å, Svensén C, Hedenstierna G. Central and regional hemodynamics during acute hypovolemia and volume substitution in volunteers. Crit Care Med 1997; 25: 635-40.

51. Hahn RG. Volume effect of Ringer's solution in the blood during general anaesthesia. Eur J Anaesth 1998; 15: 427-32.

52. Brauer L, Svensén C, Hahn RG. Kilcturgdy S, Kramer GC, Prough DS. Influence of rate and volume of infusion on the kinetics of $0.9 \%$ saline and $7.5 \%$ saline $/ 6 \%$ dextran 70 in sheep. Anesth Analg 2002; 95: 1547-56.

53. Hedin A, Hahn RG. Volume expansion and plasma protein clearance during intravenous infusion of 5\% albumin and autologous plasma. Clin Sci 2005; 106 : 
217-24.

54. Rossaint R, Bouillon B, Cerny V, Coats TJ, Duranteau J, Fernández-Mondéjar E, Hunt BJ, Komadina R, Nardi G, Neugebauer E, Ozier Y, Riddez L, Schultz A, Stahel PF, Vincent J-L, Spahn DP. Management of bleeding following major trauma: an updated European guideline. Crit Care 2010; 14: R52.

55. Dutton RP. Uncontrolled hemorrhage. In: Hahn RG, ed. Clinical Fluid Therapy in the Perioperative Setting. Cambridge: Cambridge University Press, 2011; 177-83.

56. Pirkle JC, Gann DS. Restitution of blood volume after hemorrhage: mathematical description. Am J Physiol 1975; 288: 821-7.

57. Hahn RG, Brauer L, Rodhe P, Svensén CH, Prough DS. Isoflurane inhibits compensatory intravascular volume expansion after hemorrhage in sheep. Anesth Analg 2006; 103: 350-8.

58. James MF. Place of the colloids in fluid resuscitation of the traumatized patient. Curr Opin Anesthesiol 2012; 25: 248-52.

59. Holcomb JB. Optimal use of blood producst in severely injured trauma patients. (review). Hematology Am Soc Hematol Educ Program 2010; 465-9.

60. Hahn RG. Haemoglobin dilution from epidural-induced hypotension with and without fluid loading. Acta Anaesthesiol Scand 1992; 36: 241-4.

61. Hahn RG. Blood volume at the onset of hypotension in TURP performed during epidural anaesthesia. Eur J Anaesth 1993; 10: 219-25.

\section{Appendix}

Fluid efficiency is the fraction of infused fluid that is retained in the bloodstream. A simplified expression can be obtained from the change in blood hemoglobin $(\mathrm{Hb})$ 
concentration from just before to the end of an infusion. In pigs, we assume that the blood volume at baseline $\left(\mathrm{BV}_{\mathrm{o}}\right)$ is $7 \%$ of the body weight. The change in blood volume is then obtained from before $\left(\mathrm{Hb}_{\mathrm{o}}\right)$ and after $\left(\mathrm{Hb}_{\mathrm{t}}\right)$ the infusion: ${ }^{60}$

$$
\Delta \mathrm{BV}=\mathrm{BV}_{\mathrm{o}}\left(\mathrm{Hb}_{\mathrm{o}} / \mathrm{Hb} \mathrm{t}\right)-\mathrm{BV}_{\mathrm{o}}
$$

The amount of fluid retained in the blood is then given by:

$$
\text { Fluid efficiency }(\%)=100 * \Delta \mathrm{BV} / \text { infused volume }
$$

With the double flow probe method the initial hemorrhage volume can be calculated and should be subtracted from $\mathrm{BV}_{\mathrm{o}}$. Thereafter, the capillary refill occurring before fluid therapy starts is accounted for by the $\mathrm{Hb}$ change as indicated above.

These calculations need to be performed differently if hemorrhage occurs during the actual infusion. ${ }^{61}$

Fluid efficiency is time-dependent, as apparent from Fig. 4B. This problem can be overcome by volume kinetic methods, which require serial sampling of $\mathrm{Hb}^{48}$ Calculations either compare fluids with respect to the area under the plasma dilutiontime curve following a standard infusion, or else contrast computer simulations based on differential equations. ${ }^{10}$ 


\section{Legends for figures}

Fig. 1 Principle of the double flow probe method of monitoring aortic hemorrhage in the pig. When the steel wire makes the lesion, the rate of the hemorrhage is the difference in flow between the two aortic probes. Drawing by Dr. Louis Riddez.

Fig. 2 Blood flow rates over 4 min measured at the sites shown in Figure 1 when pulling the steel wire affixed to the wall of the aorta induces uncontrolled hemorrhage. Data from Reference 4.

Fig. 3 Typical flow changes in the proximal aorta that initiates rebleeding in a pig with aortotomy at 0 min. Fluid therapy with $7.5 \%$ saline in $6 \%$ dextran 70 (HSD) increases the blood flow rate, which is boosted by the decreased resistance to flow caused by the opening of the vessel when rebleeding occurs. Based on data from Reference 16.

Fig. 4 Plasma volume expansion during and after infusing $2.7 \mathrm{~L}$ of Ringer's acetate solution over 30 minutes in an average normovolemic adult volunteer weighing $76 \mathrm{~kg}$ (A). The faction of the infused fluid that remains in the blood at any given moment (B). Simulations based on kinetic data from 8 volunteers published in Reference 49 .

Fig. 5 Plasma volume relative to baseline when Ringer's acetate solution is infused according to the 3:1 rule over 30 minutes after $900 \mathrm{ml}$ of blood has been withdrawn from male volunteers weighing $76 \mathrm{~kg}$ (A). To reach normovolemia a much smaller amount of Ringer should be infused. Titration is necessary to maintain normovolemia (B). Simulations based on kinetic data from 10 volunteers published in Reference 49. Capillary refill is estimated according to References 56 and 57. 
Fig. 6 The infusion rate and infusion time of Ringer's acetate required to restore the blood volume to normal and to modest hypovolemia of $300 \mathrm{ml}$ after withdrawal of 450 $\mathrm{ml}$ of blood (A) and $900 \mathrm{ml}$ of blood (B) in adult male volunteers weighing $76 \mathrm{~kg}$. Infusion began 30 min after the end of rapid blood withdrawal. Computer simulations based on kinetic data from Reference 49. Capillary refill was estimated to be 150 and $300 \mathrm{ml}$, respectively.

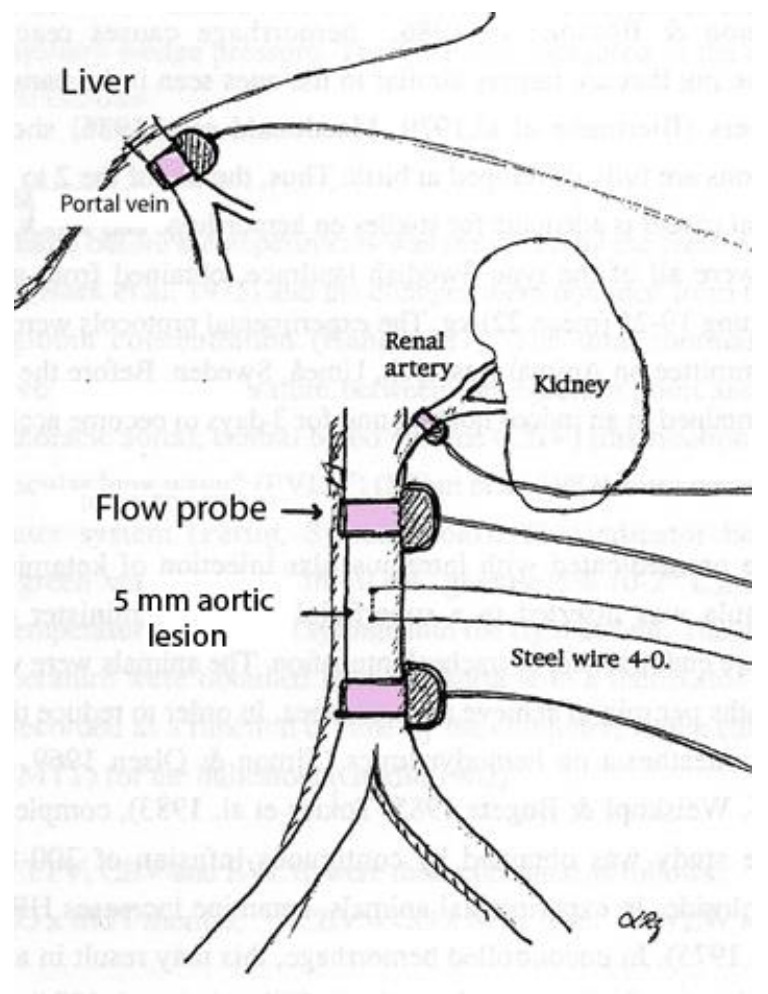

Fig. 1 


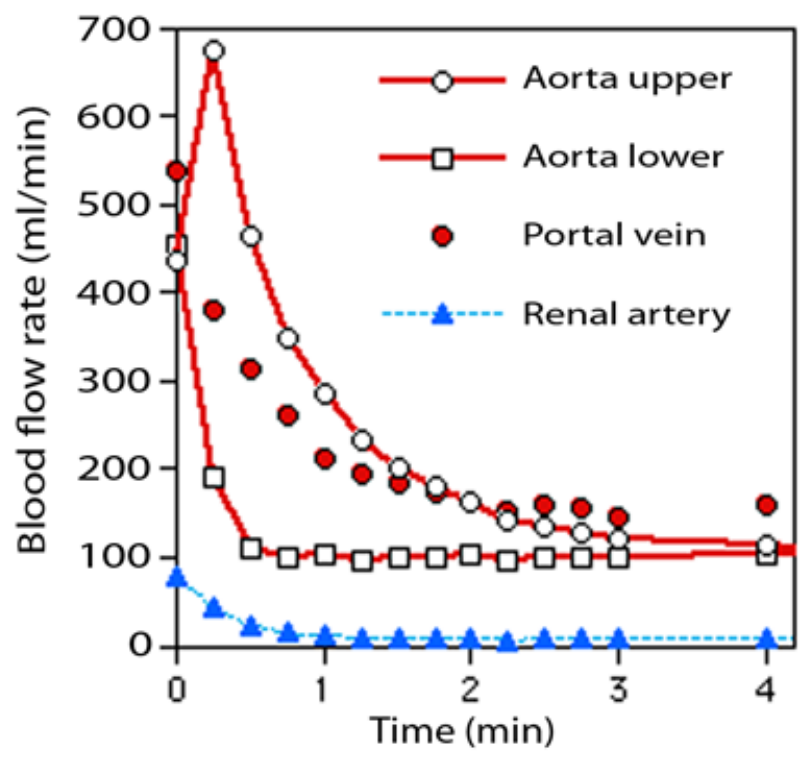

Fig. 2

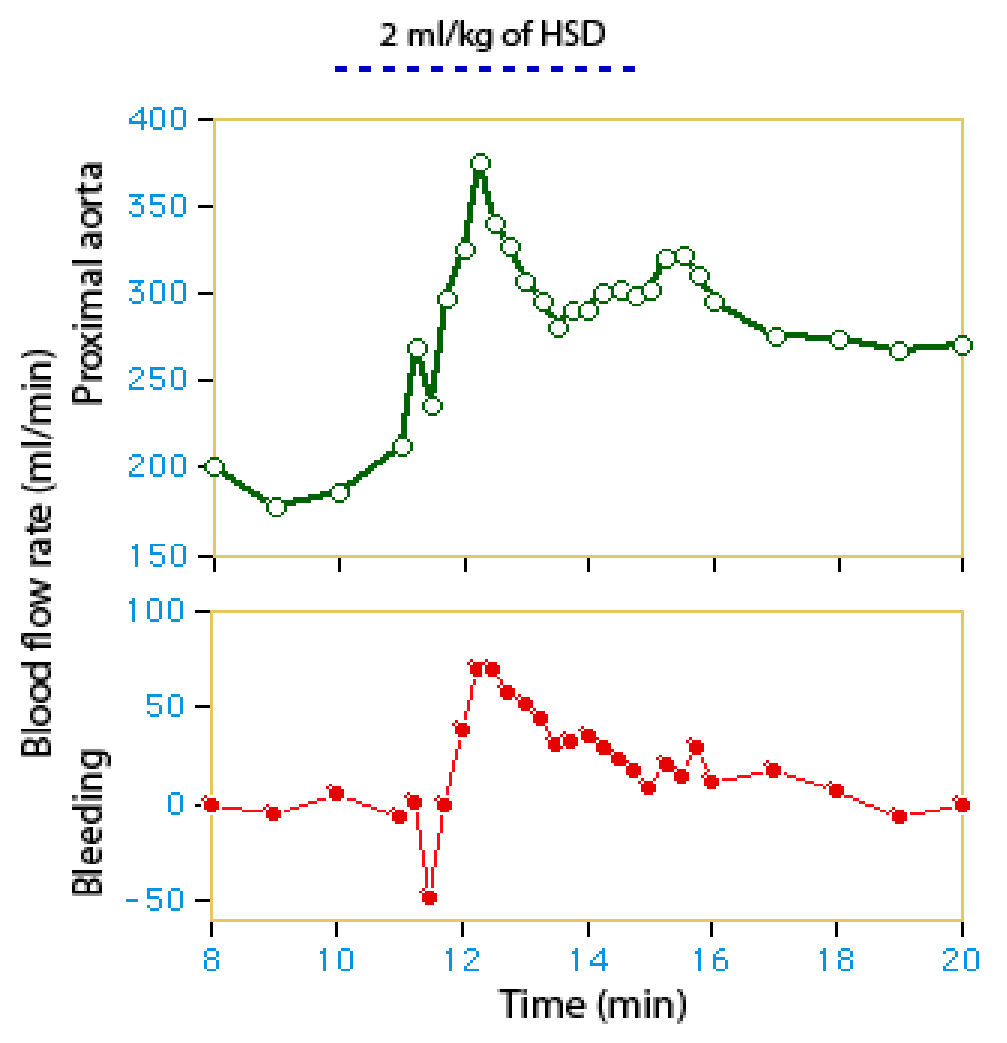

Fig. 3 

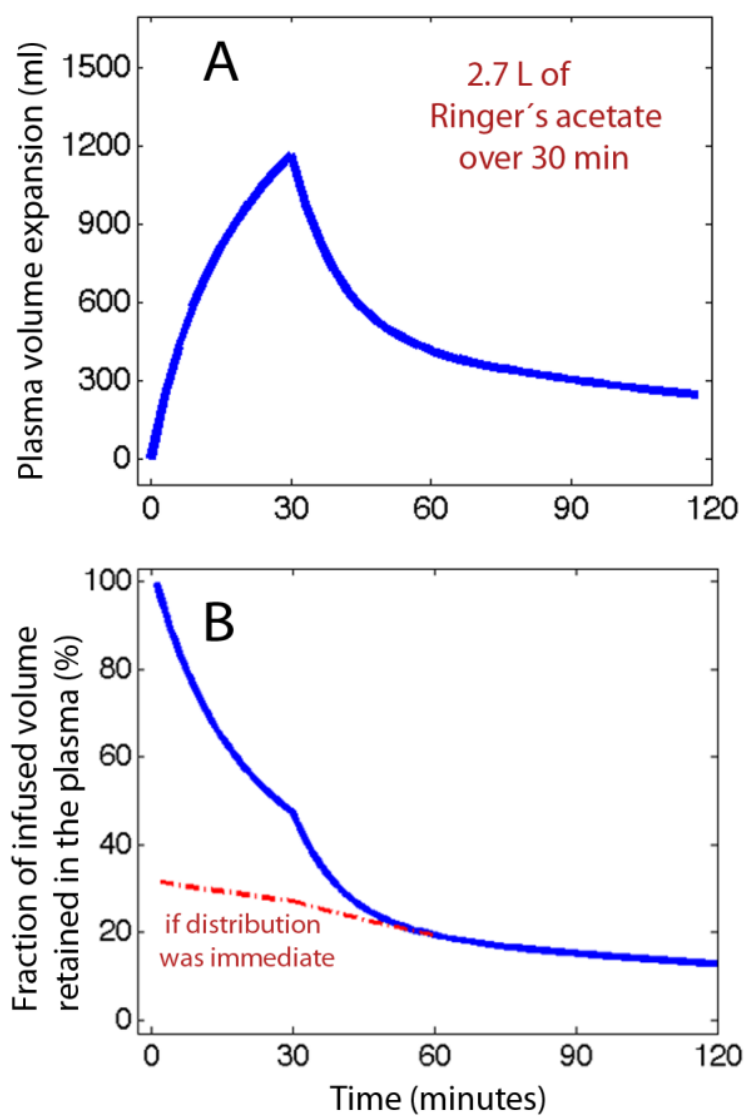

Fig. 4 


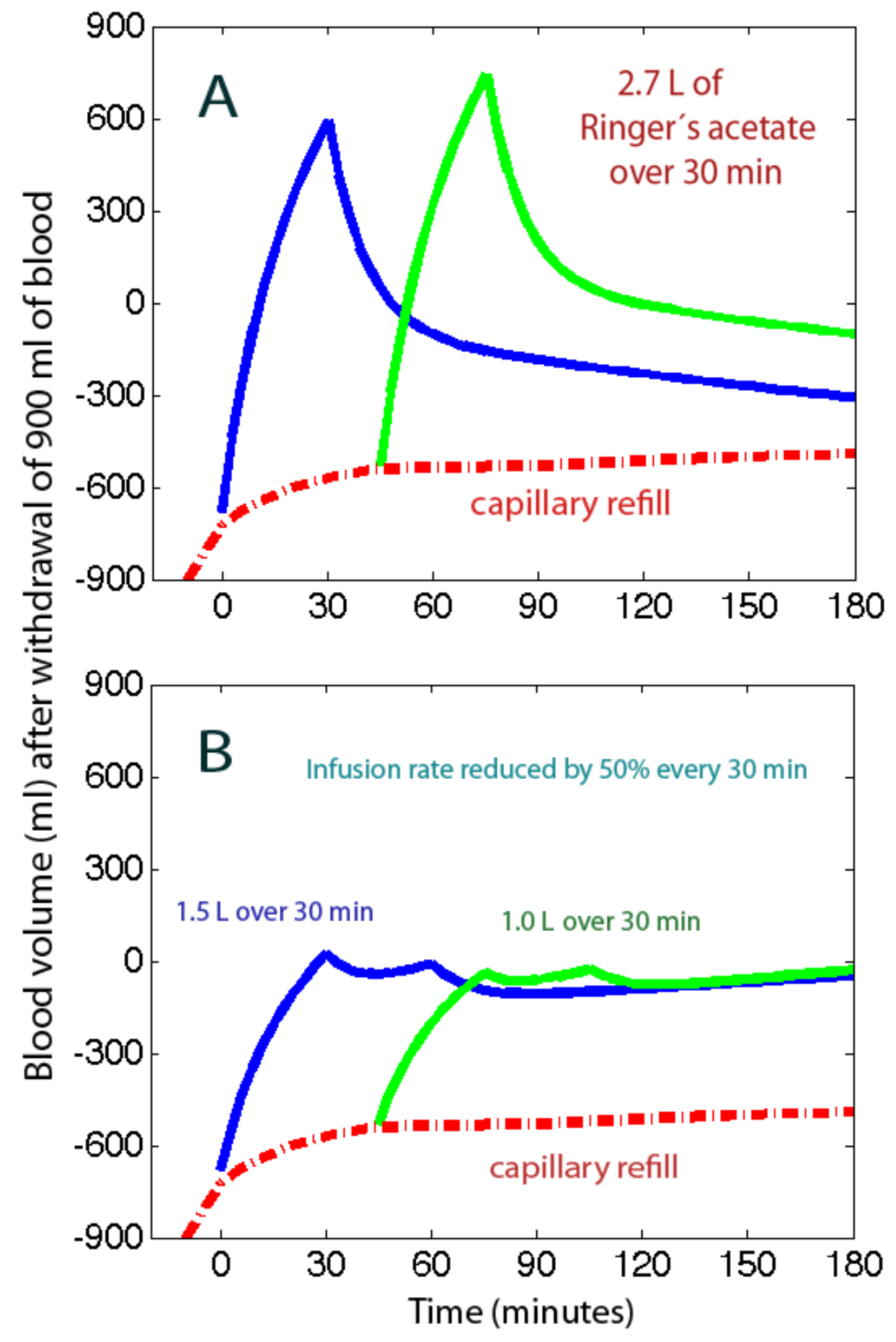

Fig. 5 


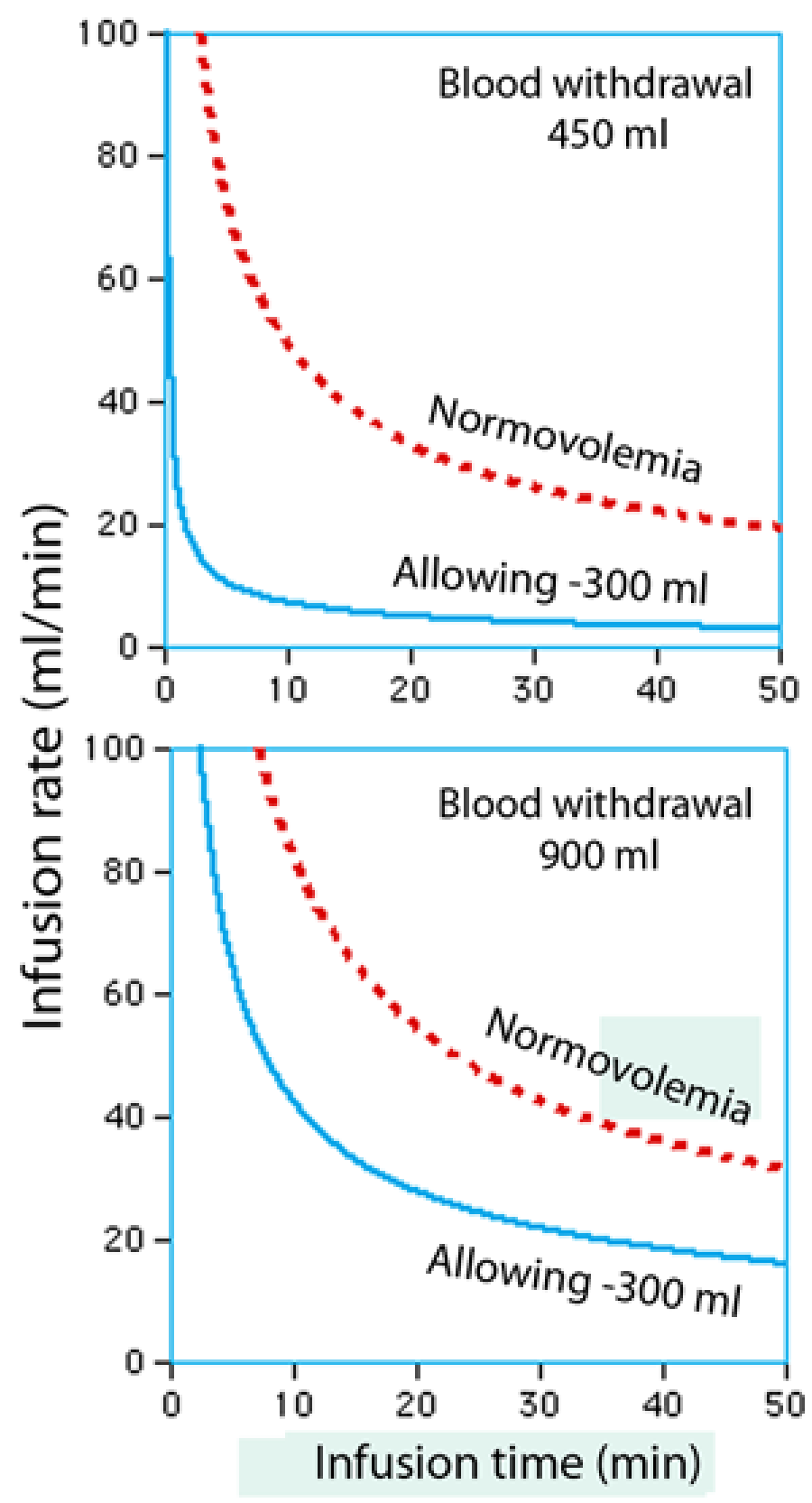

Fig. 6 